\title{
A cultura de participação do público na produção do noticiário provoca mudanças nos critérios de noticiabilidade
}

\section{Beatriz Dornelles}

Profa Dra do PPGCom/Famecos/PUCRS.

Pós-doutorado pela Universidade

Fernando Pessoa/Portugal, 2009.

E-mail: biacpd@pucrs.br

\section{Paula Renata Minozzo}

Mestranda do PPGCom/Famecos/ PUCRS.

E-mail: paularminozzo@gmail.com

\footnotetext{
${ }^{1}$ Gillmor (2004) se refere à Big Media como as empresas de comunicação que começaram a surgir no século XX e manipulavam as pessoas. Essa Big Media, segundo Gillmor (2004), são as grandes e arrogantes instituições que fazem as notícias, marketing e relações públicas hoje em dia.
}

Resumo: Neste estudo objetivamos analisar o surgimento e a atuação de sites de produção de conteúdo colaborativo em um período que discutimos as mudanças diárias ocorridas na prática de produção das notícias. O site em que usuários produzem e compartilham notícias e materiais e, por votação, elencam uma ordem do dia de histórias mais importantes, está se tornando uma alternativa fonte de informações e recebendo a atenção da mídia tradicional, que, por vez e outra, considera os rankings dos usuários um critério de noticiabilidade.

Palavras-chave: Convergência. Conteúdo Colaborativo. Reddit.

The collaborative culture in the making of the news instigates changes on the news values

Abstract: In this study we aim to better understand the emergence and performance of collaborative content production websites during a period when we discuss the changes occurring in the daily practice of the news production. The site where users produce and share news and materials and, by voting, rate an agenda of most important stories, is becoming an alternative source of information and grasping the attention of traditional media corporations, which are now beginning to consider these rankings as newsworthy.

Keywords: Convergence. Collaborative Content. Reddit.

\section{Introdução}

Produzir conteúdo no século XX era um trabalho exclusivo dos jornalistas e dos grandes veículos de comunicação. O cinema, o rádio, a televisão e o jornal detinham total poder da informação e transmitiam as notícias para uma audiência passiva, com poucas opções e possibilidades. A grande mídia, ou Big Media ${ }^{1}$ como Gillmor (2004) se refere em sua obra We The Media, tratava a notícia como uma palestra. Segundo ele, enquanto as empresas de comunicação falavam, o público ouvia, e eram elas que determinavam o que era notícia.

A interação entre a mídia e o público, no século XX, ocorria por meio de cartas ou por telefone. Quem não gostasse do que via, lia ou ouvia, tinha uma única opção: não assistir à TV, cancelar a assinatura do jornal ou desligar o rádio. A hegemonia dos grandes veículos atingiu seu pico, em meados dos anos 1960 e 1970, quando a mídia ajudou a derrubar um presidente nos Estados Unidos, e âncoras de TV eram consideradas algumas das pessoas mais confiáveis de um país. Nesse 
sistema dominado, especialmente pela TV, o conteúdo das mensagens era feito para um denominador comum, para uma massa que poderia ser homogeneizada (CASTELLS, 1999).

No entanto, foi, também, durante esse período que o surgimento dos computadores pessoais e de experimentos como a ARPANET, que logo se transformaria na internet de hoje, começaram a dar poder e ferramentas para que o público pudesse lutar contra esse monopólio da informação. Hoje, a notícia é mais parecida com uma conversa ou um seminário, o jornalismo informativo deu espaço para o opinativo, as linhas entre consumidor e produtor são cada vez mais tênues e os ouvintes, leitores e telespectadores, agora, fazem parte do processo de produção de notícias.

O crescimento da web, nos anos 1990, e o desenvolvimento de ferramentas especiais para a publicação de conteúdo e a comunicação entre os grupos começaram com os e-mails e os fóruns, antes mesmo dos Weblogs ou blogs como chamamos hoje. Esses sistemas faziam o papel de reunir membros de uma comunidade específica para a troca de informações. Gillmor (2004), em sua obra, cita o exemplo de uma lista feita entre biólogos e cientistas do mundo inteiro que dividiam descobertas sobre a Síndrome Respiratória Aguda Grave (SARS). Repórteres que estavam cobrindo e acompanhando a epidemia da doença, entre os anos 2000 e 2003, assinavam essa lista de e-mails para receberem informações em primeira mão. Segundo Gillmor (2004), pela perspectiva jornalística, listas de e-mails e fóruns podem ser um alerta ou dados científicos e seu valor nunca deve ser subestimado.

Negroponte (1995) previa que um conteúdo inteiramente diverso surgiria da digitalização da informação. A vida digital contempla, não apenas a resolução ou a qualidade da imagem da TV, mas, também, a distribuição da inteligência. Nesse novo fenômeno de digitalização, as experiências que antes eram completamente separadas estão se reunindo em um novo ambiente. Assistir à TV não é algo totalmente isolado de ler o jornal ou ouvir o rádio. As técnicas possibilitaram essa convergência entre novas e velhas mídias, assim como, também, o cruzamento entre as mídias alternativas e as corporativas.

Uma das principais mudanças de paradigmas que podemos presenciar com esse novo ambiente, que propicia a inteligência coletiva e estimula o usuário a gerar seu próprio conteúdo, é a maneira como ele se relaciona com as notícias que são veiculadas pelas mídias tradicionais. Com a presença de grandes veículos de comunicação na internet, em que seus sites possibilitam algum tipo de interatividade, como o espaço para os comentários dos leitores sobre o noticiário e a inserção de alguns conteúdos, feitos por leitores-repórteres, os novos consumidores e, agora, também produtores de informação, o público se organiza para elencar as notícias e as informações que achar importantes.

${ }^{2} \mathrm{~A}$ teoria foi desenvolvida por McCOMBS, Maxwell E. \& SHAW, Donald $L$ (ver referências).

\footnotetext{
${ }^{3}$ Acesso em www.reddit.com
}

Essa nova realidade nos conduz à reflexão sobre a hipótese da Agenda Setting ${ }^{2}$. Formulada em meados dos anos 1970, ela sustenta que os indivíduos ignoram ou se interessam por assuntos da esfera pública segundo o agendamento da mídia. Ou seja, em "consequência da ação dos jornais, da televisão e dos outros meios de informação, o público é ciente ou ignora, dá atenção ou descuida, enfatiza ou negligencia elementos específicos dos cenários públicos" (SHAW, 1970 apud WOLF, 2009, p. 143).

A hipótese da Agenda afirma que a mídia determina ao público sobre o quê falar. Mas o que estamos presenciando, a partir da convergência, é que o próprio público, por meio de sites, como, por exemplo, o Reddit ${ }^{3}$, pode publicar links de notícias (muitas vezes de sites de veículos de comunicação tradicionais), e gerar suas próprias notícias, interferindo, nesse caso, despropositadamente na agenda da mídia. 
No Reddit, as postagens dos usuários passam por uma votação em que as que recebem mais votos positivos elencam o topo das melhores histórias, ou seja, as mais interessantes. Nesse site, com caráter de rede social, os próprios usuários escolhem as suas manchetes que podem ou não serem as manchetes dadas pelos grandes jornais, sites de notícias, canais de televisão ou no rádio. Dessa forma, o público manifesta o quê para ele é notícia e determina a ordem de importância dos fatos.

Essa situação pode ser incluída na proposta de Silva (2007), que chamou de "Contra-agendamento", mas que, provavelmente pela época em que escreveu, não inclui o agendamento a partir de sites colaborativos. Mas, em sua proposição, Silva alerta para o fato de que o agendamento pode partir da sociedade para a mídia. É o reverso do que se disse ao longo de várias décadas. Silva procura fundamentar minimamente a possibilidade de transmutar o público de uma condição de simples massa de manobra à de sujeito capaz de produzir sentidos midiáticos sob um novo prisma.

Numa sociedade democrática e plural há também uma constelação de sujeitos coletivos e de respectivos lugares de fala, mas, não isolados ou encastelados em nichos corporativos, e sim, intersujeitos argumentativos, promotores e advogados de direitos e causas (SILVA, 2007, pág 84.)

A hipótese do contra-agendamento sustenta-se no fato de que a sociedade também tem as suas pautas e as deseja ver atendidas pela mídia, que tradicionalmente se utiliza dos critérios de noticiabilidade para negar a publicação de pautas sugeridas pelos leitores, ouvintes ou telespectadores. Segundo Silva (2007), esse contra-agendamento compreende um conjunto de atuações, que passam, estrategicamente, pela publicação de conteúdos na mídia e depende, para seu êxito, da forma como o tema for tratado pela mídia, tanto em termos de espaço, quanto em termos de sentido produzido.

No caso de sites colaborativos, como o Reddit, os participantes não postam notícias necessariamente preocupados em como e se a mídia vai tratar dos fatos por eles selecionados. No entanto, o efeito é bastante semelhante à proposta de Silva. Em ambos os casos, a mídia acaba sendo pautada pelo público.

\section{Cultura de convergência}

As antigas regras de comunicação de massa estão passando por uma série de mudanças, forçando os veículos jornalísticos a se adaptarem a uma nova forma de relacionamento com o público. É um período de convergências midiáticas. "Convergência é uma palavra que consegue definir transformações tecnológicas, mercadológicas, culturais e sociais, dependendo de quem está falando e do que imaginam que está falando" (JENKINS, 2009, p. 29).

A convergência das mídias, apesar de ser possibilitada pelas novas tecnologias, não é algo baseado apenas em aspectos técnicos. Essa transição, em que a informação deixa de ser composta por átomos para ser formada por bits, inverteu papeis, transformou modelos econômicos e fez uma indústria caseira de informação e entretenimento surgir. (NEGROPONTE, 1995). Pensar comunicação de massa, após as transformações tecnológicas, não se restringe em pensar nas mídias tradicionais e nos grandes veículos de comunicação.

A convergência representa uma transformação na qual o fluxo comunicacional não é mais uma via de mão única, que transmite informações moldadas e padronizadas para uma audiência passiva. O fluxo comunicacional na cultura de convergência não somente incentiva como, também, depende da participação 
ativa dos consumidores. Hoje, antigos conceitos estabelecidos sobre meios de comunicação não fazem mais sentido.

Redes digitais estão aumentando a fluidez de todas as mídias. A velha escolha entre mídia pública de mão única (como livros e filmes) e mídia privada de mão dupla (como o telefone) expandiu-se e inclui agora uma terceira opção: mídia de mão dupla que opera numa escola do privado para o público (SHIRKY, 2011, p. 53).

Mas como isso influencia e implica a maneira como as pessoas mudaram em relação às mídias tradicionais? Com novas ferramentas e novas possibilidades, com um computador pessoal e internet, o que a cultura de convergência mudou na maneira de as pessoas consumirem conteúdos agora que elas também podem produzi-los? A cultura de convergência é altamente produtiva. Os fãs e os consumidores da contemporaneidade comportam-se de maneira a não aceitar imposições e providenciam forma de participar da criação e produção do que eles mesmos consomem (JENKINS, 2009).

Visando à atenção desse novo modelo de consumidor, que também é produtor, as grandes empresas de informação e entretenimento, para não perderem a audiência, bem como para conquistar um novo público, buscam formas de adaptação ao novo cenário. A narrativa transmídia, para contar uma história e fazer com que o público tenha experiências diferentes, em diversos canais, sobre uma mesma obra, é fruto da cultura de convergência. Essa narrativa foi feita para matar a fome de informação, e um exemplo disso é o filme Matrix, de 1999, uma das primeiras franquias a se adaptar à nova cultura e a adaptar conteúdos para diferentes plataformas. Matrix pode ser tanto um atrativo cultural quanto um ativador cultural (JENKINS, 2009).

Como experiência mais recente, destacamos a série The Walking Dead, do canal AMC, baseado em histórias em quadrinhos e estreado na televisão norteamericana em 2010. O próprio seriado instiga o telespectador a comentar o

${ }^{4} \mathrm{O}$ símbolo do sustenido (\#), que se chama hashtag, em inglês, é usado antes de certas palavras no microblog Twitter, pelos internautas, para contextualizar o assunto sobre o qual eles falam. Os termos acompanhados do símbolo tornam-se links que podem ser clicados para localizar outros usuários que estão falando sobre o mesmo assunto e usando a mesma hashtag.

${ }^{5}$ Dado retirado de 4 ww.reddit.com about episódio, que está no ar por meio do Twitter, pela hashtag \#thewalkingdead ${ }^{4}$, que aparece no canto esquerdo da tela, no começo da história. Além disso, a franquia The Walking Dead inclui produtos diversos, como jogos, sites e canais de vídeo on-line para a divulgação dos próximos episódios. Assim como o Matrix, a produtora do seriado da AMC disponibilizou e produziu o conteúdo para diversos canais, não só porque a tecnologia permite que isso seja feito, mas porque é o que o público quer e procura. "Para apreciar verdadeiramente o que estamos vendo, temos de fazer a lição de casa" (JENKINS, 2009, p. 137).

As mídias corporativas reconhecem, cada vez mais, o poder do público e estão trabalhando para não ficarem de fora desse cenário. Ao mesmo tempo, o público usa as novas tecnologias e as mídias sociais para se envolver com o conteúdo das mídias tradicionais de uma nova maneira, alerta Jenkins (2009).

\section{O Site REDDIT}

Fundado em 2005, o site Reddit possui, hoje, mais de 1, 3 milhão usuários ${ }^{5}$ ou redditors, como são chamados, nessa palavra que mistura Reddit e editors (editores, em inglês). Dentro do site, é possível que os usuários se dividam em comunidades de interesses, denominadas subreddits, votem e comentem em histórias, fotos ou qualquer tipo de link compartilhado. Entre todas essas possibilidades, os usuários também podem adicionar os outros como amigos e trocar mensagens. No site cada usuário possui um perfil pessoal, sem foto ou descrição, nada parecido como, por exemplo, os perfis no Facebook. No site, a página pessoal de cada pessoa mostra os links e os conteúdos que ela submeteu e qual foi a repercussão desses dentro do site. O Reddit possui múltiplas funções e consegue unir elementos de sites de 
${ }^{6}$ Fonte de notícias.

redes sociais a plataformas de publicações sociais. Segundo Recuero (2009), uma rede social é definida por ter dois elementos: atores e conexões. Os atores seriam as pessoas, grupos ou instituições; e as conexões, os laços sociais ou interações.

Além disso, é um site Open Source ou, em português, "código aberto", que significa que os próprios usuários podem colaborar com a melhoria do site, assim como adicionar novos recursos. Gillmor (2004) fala sobre as vantagens de sites Open Source para modelos de negócios e, especialmente, para o jornalismo. Segundo Gillmor (2004), sites como o Reddit fazem parte do fenômeno Open Source de organizações emergentes e independentes que não apenas abrem o código de seus sites para o conserto de problemas, mas fazem um trabalho respeitável em escolher e filtrar as notícias para quem quiser. O fenômeno Open Source, descrito por Gillmor (2004), é apenas o começo de algo muito maior que pode transformar o fazer jornalístico.

Ao longo de sete anos, o site foi adicionando certas funções, como comentários e comunidades, e se tornou Open Source. Podemos conceituar o Reddit como sendo um site de uma grande comunidade de interesses, compartilhamento de notícias e produção de conteúdo, e que permite a ramificação e a formação de subcomunidades dentro dele. Cada usuário tem o poder de personalizar a sua página inicial e as categorias que quer assinar para receber o feed ${ }^{6}$ de links. As categorias são variadas, como: Gaming (videogames), Politics (política), Videos, World News (notícias internacionais), Aww (o que seria uma seção para coisas 'fofas', em que vídeos e notícias de animais predominam) e WTF (para links sobre situações insólitas) como fotos de policiais falando ao celular enquanto dirigem.

Depois de abordar a cultura de convergência e a necessidade do público de atuar participativamente nos conteúdos e produtos das mídias tradicionais, deve-se explorar a necessidade que as pessoas possuem de selecionar os seus próprios materiais para consumo e as razões que as levam a buscar sites que têm o conteúdo selecionado por outros usuários. A formação de comunidades para a troca de conteúdos específicos é algo que atrai redditors, por possibilitar editorias, como o AWW e o WTF, citados acima, que vão além das propostas pela mídia tradicional.

Até a chegada da internet e da popularização das redes, as pessoas estavam expostas a uma mensagem homogeneizada e única, que pretendia falar para todas as massas. Agora, no entanto, cada vez mais o mercado de massa se converte em mercado de nicho.

Ainda existe demanda para a cultura de massa, mas esse já não é mais o único mercado. Os hits hoje competem com inúmeros mercados de nicho, de qualquer tamanho. E os consumidores exigem cada vez mais opções. A era do tamanho único está chegando ao fim e em seu lugar está surgindo algo novo, o mercado de variedades (ANDERSON, 2006, p. 7).

O Reddit possui características desse novo mercado em que blogueiros e produtores amadores têm seu próprio público. No site, quem tem um cachorro, por exemplo, pode produzir vídeos que talvez possam se tornar populares entre aqueles que consomem a categoria $A w w$. As preferências das pessoas se afastam de uma tendência dominante, imposta pelos tradicionais veículos de comunicação ou pela indústria de entretenimento. Além disso, Anderson (2006), em Cauda Longa, faz uma comparação da duração de programas de TV e os vídeos produzidos por internautas, levando em consideração os programas com tempos fixos e padronizados como, por exemplo, os de meia-hora das emissoras de televisão: 


\begin{abstract}
Como várias outras convenções que hoje aceitamos como escolhas culturais, a programação rígida de produzir vídeos em múltiplos de trinta minutos é, na realidade, conseqüência das ineficiências de distribuição. Um dia, essa convenção talvez desapareça, substituída por ampla variedade de conteúdo com duração mais natural, que reflita a diversidade do alcance da atenção humana por tipo de atração, em vez de basear-se na conveniência da programação e nas prioridades dos anunciantes (ANDERSON, 2006, p. 132).
\end{abstract}

No ambiente externo à televisão, vídeos elaborados por amadores possuem durações diversas sem padrões de duração, e, como foi abordado por Jenkins (2009), o consumidor e, agora, produtor, não quer nada imposto, nem mesmo o tempo de duração de um programa. "O importante é o que nós queremos; não o que o canal de distribuição quer" (ANDERSON, 2006, p. 133).

Os usuários, no Reddit, são chamados de editores por elencarem quais conteúdos são mais relevantes ou devem ficar no topo do site, muito similar à função de uma manchete. Assim, ao entrar no site, a primeira história ou link a ser visto é o primeiro, que é indicado por setas e quantas pessoas clicaram para mover esse conteúdo ao primeiro lugar do site.

Na imagem 1, podemos ver que, no canto esquerdo da página, as histórias mais votadas são enumeradas. As setas podem ser clicadas para que o usuário cadastrado possa classificar se a história deve continuar nas primeiras colocações (com a seta direcionada para cima) ou se deve cair (para baixo).

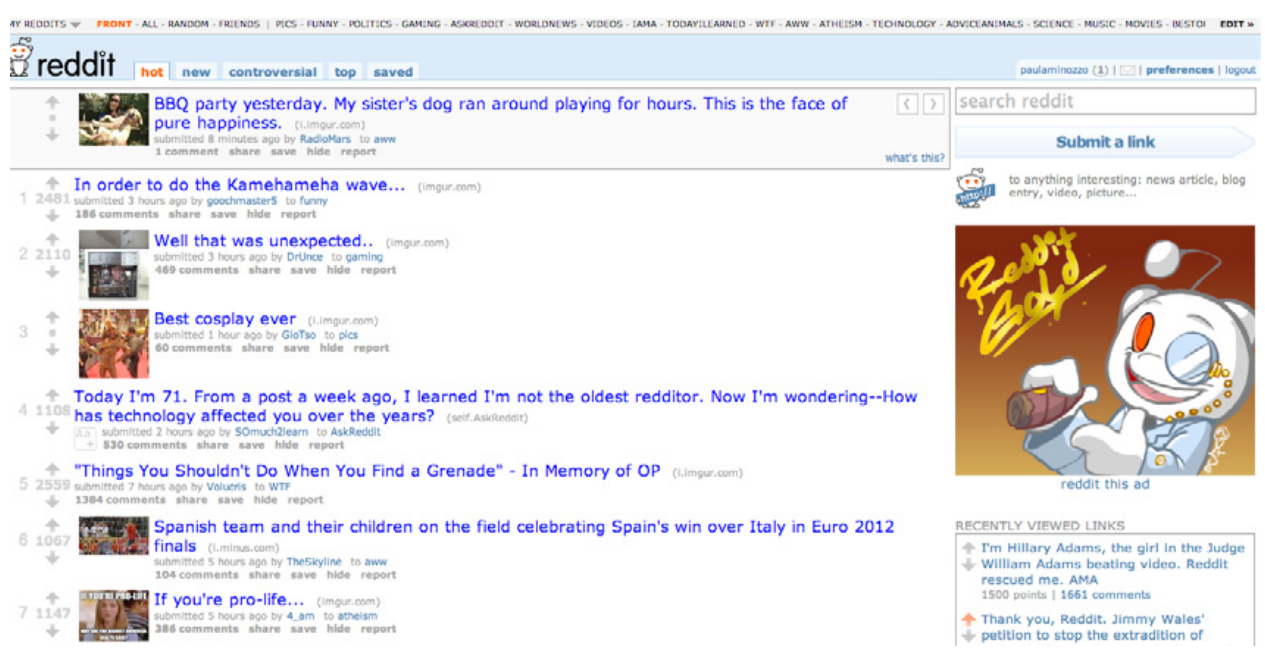

Figura 1 - Print Screen do Site Reddit

Em meio a conteúdos produzidos por internautas, constaram no site Reddit algumas notícias de sites de tradicionais veículos de comunicação, como Los Angeles Times e The Guardian. Isso mostra que, apesar de procurarem conteúdos produzidos pelos próprios redditors, assim como uma ordem do dia de acontecimentos feita por eles mesmos, os usuários não ignoram as notícias veiculadas pelos tradicionais veículos de comunicação.

${ }^{7}$ Resultados da pesquisa disponíveis em: www.journalism.org/node/7493. Tradução livre: Projeto para Excelência em Jornalismo.

${ }^{8}$ Site de mídia tradicional é chamado na língua inglesa de mainstream.
Um estudo conduzido pelo Project for Excellence in Journalism (PEJ) ${ }^{7}$, analisou o Reddit e outros dois sites similares, o Digg e o Del.icio.us, e comparou as histórias mais populares, nesses sites, com as de 48 sites de mídias tradicionais. A pesquisa constatou que, a maioria do conteúdo que o usuário nos sites colaborativos elencava como importante, não estava na agenda dos sites da mídia tradicional ${ }^{8}$. Além disso, $70 \%$ do conteúdo compartilhado nos sites eram provenientes de blogs ou gerados pelos usuários. Apenas 30\% vinham da mídia tradicional.

Se a agenda da mídia faz parte de uma pequena porção dos interesses dos usuários nesses sites, teria o Reddit o poder de pautar a mídia tradicional? Esses sites estariam influenciando os valores-notícias que determinam quais histórias 
${ }^{9}$ Em tradução livre: Cara Ridiculamente Fotogênico.

${ }^{10}$ Matéria completa pode ser acessada em $>$ abcnews.go.com/blogs/ headlines/2012/04/ridiculouslyphotogenic-guy-explains-photo-op
${ }^{11} \mathrm{O}$ termo meme é um conceito de replicação de ideias (RECUERO, 2009). Na internet, é usado para classificar imagens ou vídeos altamente reproduzidos pelos internautas e que podem ser alterados ou reutilizados para transmitir ideias ou uma piada.

${ }^{12} \mathrm{~A}$ matéria está disponível em: $\triangleleft$ today. msnbc.msn.com/id/45135221/ns/ today-today_news/t/judges-daughterhope-beating-video-gets-him-help/\#. TrLIPnLf9MPP. serão abordadas pela mídia? Algumas situações pontuais já estão acontecendo. Uma delas é uma imagem engraçada de um maratonista, editada e publicada por um dos usuários do Reddit, que ganhou o nome de Ridiculously Photogenic Guy ${ }^{9}$. A foto ganhou tamanha repercussão no site que se tornou pauta de um dos programas de televisão da rede americana $A B C^{10}$, uma das maiores emissoras do país.

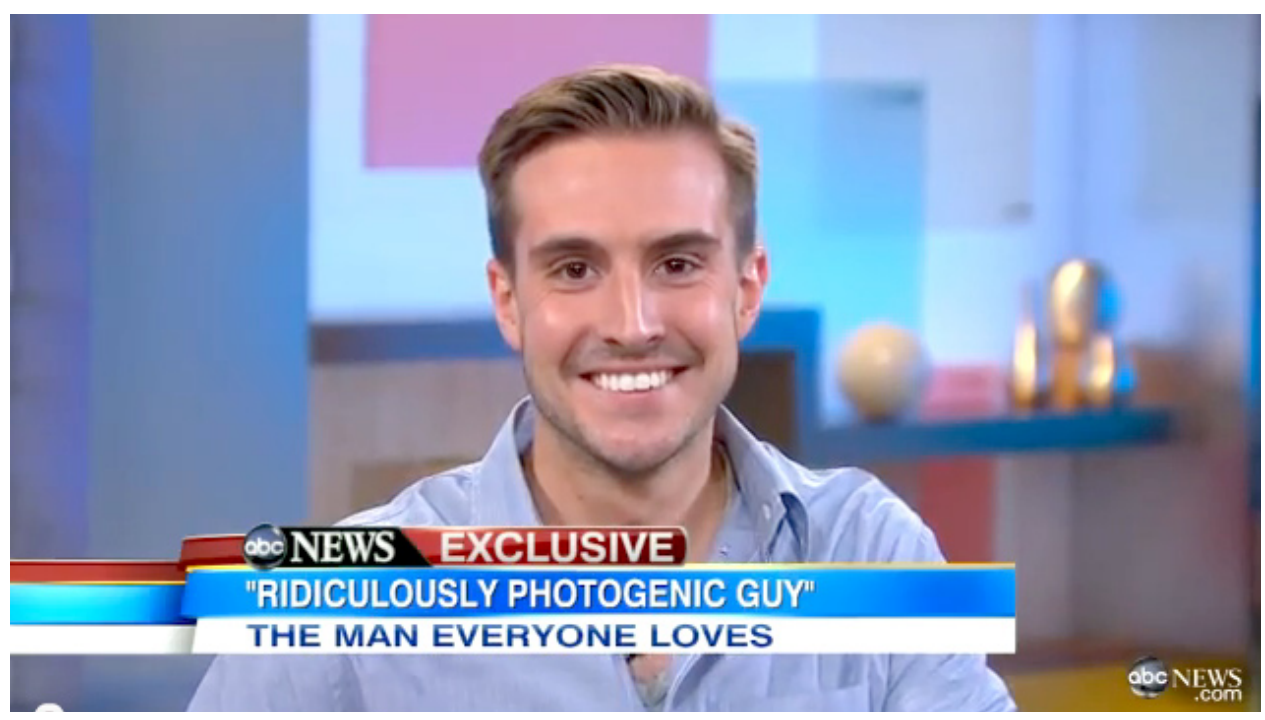

Figura 2 - Ridiculously Photogenic Guy no canal $A B C$

Em entrevista, o canal ABS se referiu ao americano como o homem que todos amam.

No programa, a apresentadora Robin Roberts entrevista o maratonista da foto, assim como o fotógrafo responsável pela imagem. O Ridiculously Photogenic Guy foi um meme ${ }^{11}$ que transcendeu a esfera da internet e os sites colaborativos. Assim que os usuários-editores tomaram conhecimento sobre a matéria da $A B C$, um novo tópico foi compartilhado, no site, com a notícia e o vídeo da entrevista. Apesar de o estudo do PEJ ter demonstrado que os assuntos pautados pela mídia formam uma pequena fração do que os usuários do Reddit compartilham, o fato de um meme, difundido pelo site, ter espaço nos canais de mídia é algo a ser comemorado.

Outra situação que surgiu por meio do Reddit, e logo tomou as manchetes das mídias tradicionais, foi o caso da jovem, Hillary Adams, que, aos 16 anos, filmou, com uma câmera digital, uma situação em que era agredida por seu pai, um juiz da vara da família nos Estados Unidos. Anos depois, quando já estava morando sozinha, a jovem lançou o vídeo no Reddit. A MSNBC ${ }^{12}$ tomou conhecimento da história e chamou a vítima e sua mãe para uma entrevista no programa Today, da TV americana.

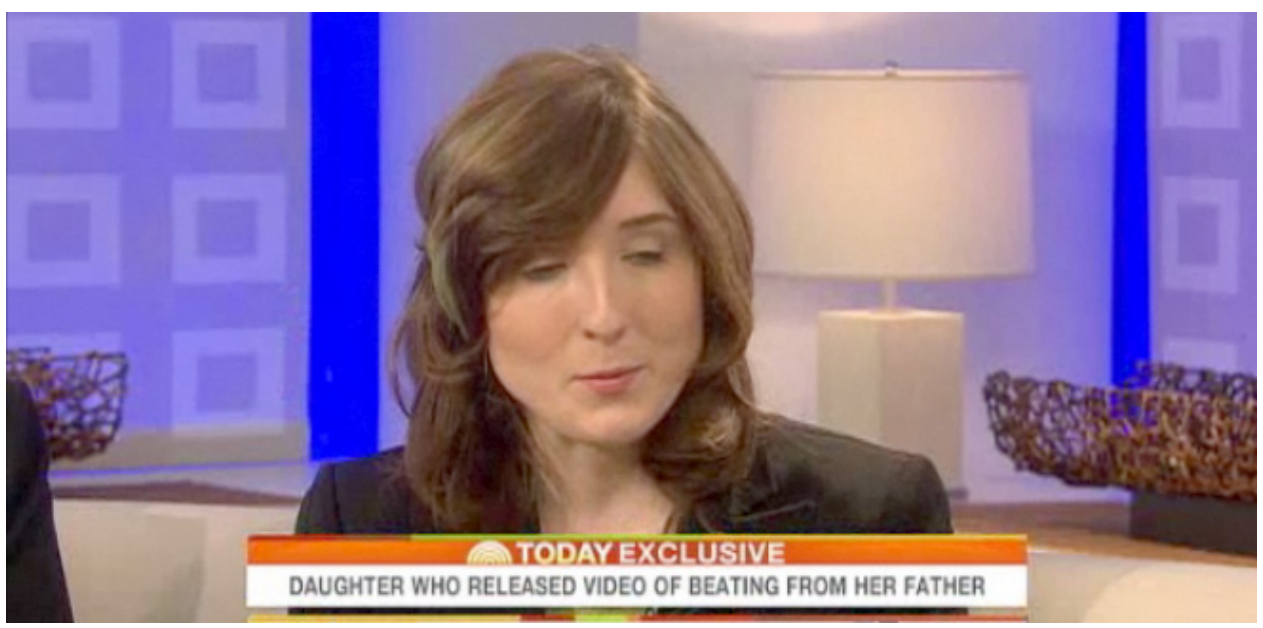

Figura 3 - Hillary Adams no Today

Hillary Adams conta sua história na televisão americana 
Em ambas as situações, as notícias abordadas pela mídia tiveram a atenção das emissoras de televisão MSNBC e ABC por terem sido consideradas populares pelos usuários da internet. A notícia da jovem, que era agredida por seu pai, um juiz americano, teria critérios de noticiabilidade ou valores-notícias suficientes para ser pauta, visto que inclui interesse humano. Já o caso do maratonista, a matéria, em si, aborda, apenas, o sucesso da foto na internet, uma vez que o homem não era uma figura conhecida, mas ficou famoso por ter uma imagem sua em uma montagem que circulou pela internet por ter sido considerada "engraçada".

\section{Considerações finais}

Uma reflexão em torno do histórico do site Reddit nos fornece elementos para compreender o comportamento dos jovens consumidores de notícias, através de sites colaborativos. Confirma-se o que, há muitos anos, pesquisadores das Ciências Sociais vêm alertado em textos científicos: os jornalistas dizem que sabem o que o público deseja saber, mas, na verdade, estão em rota de colisão com as pessoas que consomem notícias.

Um dos exemplos que analisamos, o caso Ridiculously Photogenic Guy, que virou pauta de emissoras jornalísticas, revela um critério de noticiabilidade impensável para os profissionais que atuam em redações noticiosas de rádios, TVs e jornais. No máximo, poderia ser fonte de inspiração de chargistas, mas dificilmente geraria uma pauta para reportagem, já que o principal atrativo da notícia era o "ridículo", termo que não faz parte dos critérios de seleção das notícias pelos jornalistas.

Além disto, é importante pensarmos sobre a pesquisa realizada pelo Project for Excellence in Journalism (PEJ), que comparou as histórias mais populares em sites colaborativos com 48 sites de mídias tradicionais. O resultado foi que $70 \%$ do conteúdo compartilhado nos sites eram provenientes de blogs ou gerados pelos usuários. Ou seja, originavam de pessoas que não foram treinadas para decidir e selecionar o que é ou não de interesse público. Apenas 30\% das histórias selecionadas pelos usuários-editores provinham das páginas produzidas por jornalistas. Ou seja, 70\% da produção jornalística não interessam a esse público, que agendou outros acontecimentos para discutir ao longo do dia. É bastante plausível acreditar que esse índice se repita por jornais do mundo inteiro, se submetidos a uma pesquisa.

Verificamos que o site Reddti, assim como outros de mesma natureza, possibilitou tornar público o que realmente interessa aos consumidores de notícia, que, além de contrariarem os critérios de noticiabilidade da mídia tradicional, também manifestam interesse em produzir pautas e notícias. E mais do que isso: podemos constatar uma carência de algumas interveniências na hipótese da Agenda Setting, que diz que a sociedade tende a incluir ou excluir do debate os temas que a mídia inclui ou exclui do seu próprio sistema de seleção de assuntos. O que está ocorrendo, conforme análise dos casos apresentados, é a hipótese do Contraagendamento, termo denominado por Silva (2007), que significa o agendamento que parte da sociedade para a mídia.

Analisando as funções e os recursos do Reddit, observamos que o site não pode ser descrito como uma rede social, mas, também, não é apenas uma plataforma que possibilita a produção colaborativa, como, por exemplo, a Wikipedia, uma vez que os usuários possuem uma identidade e um perfil pessoal. Além disso, o Reddit apresenta claramente três características básicas do Jornalismo: atualidade, periodicidade e disseminação de acontecimentos de interesse público (ou de parte do público).

Diante das novas ferramentas tecnológicas, que permitem a participação efetiva do público na escolha dos temas que devem ser discutidos pela mídia, acreditamos ser plausível afirmar que, em muitas situações, a produção de material veiculado 
na internet está pautando a agenda dos tradicionais veículos de divulgação de notícias: rádio, TV e jornal. Com isso, os jornalistas e produtores de notícia terão de rever seus critérios de noticiabilidade.

\section{Referências bibliográficas}

ANDERSON, Chris. A Cauda Longa. Rio de Janeiro: Elsevier, 2006

CASTELLS, Manuel. A sociedade em rede. A era da informação: economia, sociedade e cultura. São Paulo: Paz e Terra, 1999

GILLMOR, Dan. We the Media - Grassroots by the people, for the people. Sebastopol: O'Reilly Media, 2004.

JENKINS, Henry. Cultura da Convergência. São Paulo: Aleph, 2009

McCOMBS, Maxwell E. \& SHAW, Donald L. A evolução da Pesquisa sobre o agendamento: vinte e cinco anos de Mercado de ideias, 1993. In: TRAQUINA, Nelson. O poder do jornalismo: Análise e textos da teoria do agendamento. Coimbra: Minerva, 2000.

. A função do agendamento dos media, 1972. In: TRAQUINA, Nelson. O poder do jornalismo: análise e textos da teoria do agendamento. Coimbra: Minerva, 2000.

NEGROPONTE, Nicholas. A vida digital. São Paulo: Companhia das Letras, 1995

RECUERO, Raquel. Redes Sociais na Internet. Porto Alegre: Sulina, 2009

SILVA, Luiz Martins da. Sociedade, esfera pública e agendamento. In: BENETTI, Márcia; LAGO, Cláudia. (Org.). Metodologia de pesquisa em jornalismo. 1 ed. Petrópolis: Vozes, 2007, v. 1, p. 84-104.

SHIRKY, Clay. A cultura da participação. Rio de Janeiro: Zahar, 2010

WOLF, Mauro. Teorias das comunicações de massa. São Paulo: Martins Fontes, 2009. 